\title{
ORIGEM E ALTERAÇÃO NO PENSAMENTO LINGUÍSTICO-MUSICAL DE ROUSSEAU
}

\begin{abstract}
Mauro Dela Bandera ${ }^{1}$
Resumo: A linguística de Rousseau transita entre dois polos distintos, mas igualmente válidos, quais sejam, o saber antropológico e o julgamento histórico do estado presente. O objetivo maior deste trabalho é apresentar cada um destes polos: o último apoia-se em um modelo único e originário de língua (uma protolinguagem) que paulatina e historicamente se degeneraria, corrompendo-se; ao passo que o primeiro multiplica as origens de modo a afirmar positivamente as diferenças, explicando-as enquanto tais. Um se constitui em escala de medida, outro em antídoto contra o etnocentrismo.

Palavras-chave: Rousseau - linguagem - música - antropologia - história.
\end{abstract}

Um ar de mistério ronda há muito tempo o Ensaio sobre a origem das línguas de JeanJacques Rousseau. Sabemos que o texto apareceu apenas em 1781 (três anos após a morte do autor) em um volume, intitulado Tratados sobre a música, publicado na cidade de Genebra. Desde pelo menos o final do século XIX, foram travadas inúmeras contendas a seu respeito, tão difíceis de serem resolvidas quanto a quadratura do círculo. O período e as condições em que o livro foi escrito constituem ainda hoje matéria de controvérsia entre os comentadores. Os intérpretes e historiadores mais autorizados raramente chegaram a um acordo sobre isso e quando o fizeram, é em geral por diferentes razões. O parentesco com o Discurso sobre a desigualdade é facilmente perceptível em vista do capítulo IX do Ensaio - que trata da formação das primeiras sociedades -, mas se há aí uma derivação ou elaboração independente não é nada fácil decidir, e a presença das discussões musicais, praticamente ausentes do Discurso sobre a desigualdade, torna ainda mais difícil estabelecer a posição da obra no percurso do pensamento do autor. O problema aumenta substancialmente pelo fato do Ensaio ser um texto sobre o qual Rousseau pouco se explicou e, quando o fez, sempre demonstrou certa reticência ${ }^{2}$.

\footnotetext{
1 Professor adjunto do Centro de Filosofia e Ciências Humanas da Universidade Federal do Acre (UFAC). E-mail: maurodelabandera@yahoo.com.br.

2 Sobre a gênese e a cronologia do Ensaio, bem como sua relação com os demais escritos de Rousseau, ver nosso artigo "Questões de cronologia rousseauísta: o caso do Ensaio sobre a origem das linguas".
} 
Dito isto, analisaremos neste artigo a teoria da linguagem desenvolvida por Rousseau, procurando traçar algumas relações com outros escritos do autor, particularmente, os textos sobre música ${ }^{3}$, o Discurso sobre a desigualdade e o Contrato social. O percurso escolhido passará necessariamente por algumas emaiparagens marcantes do pensamento linguístico de Rousseau: a posição ocupada pelas reflexões musicais nas páginas do Ensaio, sobretudo no discurso sobre a origem; a questão da degeneração das línguas que, justamente, vem alterar esta origem; e, por fim, a pluralidade de origens possíveis para as línguas. Este itinerário nos levará a compreender a articulação de duas perspectivas interpretativas, ambas presentes no texto de Rousseau: i) uma de tipo primitivo-defletivo que parte de um modelo primeiro/originário e encara a história como um processo que se realiza enquanto degeneração e afastamento; ii) outra de tonalidade antropológica que não se contenta com a unidade de uma só origem, mas que multiplica as origens de modo a afirmar positivamente as diferenças, aspirando entendê-las enquanto tais.

\section{"Cantar-se-ia em lugar de falar"4}

Para iniciarmos nossa investigação, imaginemos um leitor desavisado que pega ao acaso o Ensaio de Rousseau e a partir do título arrisca formular algumas hipóteses sobre o conteúdo do livro e fazer um plano de leitura. Seu título completo é Ensaio sobre a origem das línguas: no qual se fala da melodia e da imitação musical. O filósofo anuncia duas partes, a primeira concernente às línguas e a segunda à música sob dois aspectos precisos: a melodia e a imitação. A mesma divisão de matérias aparece na disposição dos capítulos: alguns versam sobre a linguagem e as línguas e outros abordam questões fundamentalmente musicais. Esse leitor imaginário provavelmente se surpreenderá com a relação entre reflexões sobre a linguagem e teoria musical. O que significa, questionará ele, afirmar que a música e a língua possuem entre si alguma afinidade ou algum laço que as une? Ou melhor, qual é o lugar da música no quadro da teoria da linguagem de Jean-Jacques Rousseau e na economia do Ensaio? Será que se poderia pensar que se trata apenas de um paralelo sem maiores consequências para a argumentação do autor ou essa aparente confusão de temas esconde uma lógica profunda e rigorosa?

Para melhor elucidar esse ponto, vale a pena citar uma passagem em que Paul Valéry anuncia a separação existente entre as palavras e a música:

Que se evoque a linguagem e a melodia primitiva, a separação das palavras e da música, a arborescência de cada uma, a invenção dos verbos, da escrita, a complexidade figurada das frases tornando-se possível, a intervenção tão curiosa das palavras abstratas e, de outra parte, o sistema dos sons se

\footnotetext{
3 Uma peculiaridade interessante dos textos de Rousseau concernentes à música e à linguagem é que cada um deles se contamina com elementos dos demais. O Ensaio sobre a origem das linguas, o Princípio da melodia, o Exame dos dois princípios, os artigos da Enciclopédia, a Carta sobre a música francesa e o Dicionário de música são todos textos que se comunicam entre si, trocam fragmentos, implicam-se e confundemse.

${ }^{4}$ ROUSSEAU, Essai sur l'origine des langues, OC, V, p. 383.
} 
formando, estendendo-se da voz à ressonância dos materiais, aprofundandose pela harmonia, variando-se pelo uso dos timbres ${ }^{5}$

Rousseau nos oferece, a propósito da relação entre música e linguagem, uma concepção que se encontra nos antípodas daquela apresentada na Introdução ao método de Leonardo da Vinci. O autor de forma alguma admite "a separação das palavras e da música", tal como evocada acima por Valéry. A seu ver, música e língua formavam um todo original e necessariamente constituído, um todo coeso, de modo que não se sabia mais até que ponto se fazia "cantar a língua e falar a música". A consubstancialidade originária da música e da língua é afirmada logo no final do capítulo II do Ensaio, no momento em que Rousseau diz que "as primeiras línguas foram cantantes e apaixonadas" .

Quando a palavra eclodiu, no início da sociabilidade humana, não haveria distinção entre música, poesia e discurso.

Os primeiros discursos foram as primeiras canções: os retornos periódicos e compassados do ritmo, as inflexões melodiosas dos acentos, fizeram nascer, com a língua, a poesia e a música, ou melhor, tudo isso não era outra coisa senão a própria língua ${ }^{8}$.

As línguas eram musicais, pois promoviam uma sucessão rítmica de sons diversamente modulados. Não poderia ser diferente já que a impressão sucessiva dos acentos formava uma melodia, com tons e ritmos próprios de uma música.

A ocorrência da música no capítulo II do Ensaio é reveladora. Confirma que Rousseau privilegia a voz humana e não qualquer tipo de manifestação musical. Seus textos linguísticomusicais valorizam o aspecto vocálico que se apresenta imediatamente sob a forma da melodização. A melodia é definida no verbete homônimo do Dicionário de música como a "sucessão de sons ordenados de tal maneira segundo as leis do ritmo" (entendido como diferença na duração/valor dos sons) "e da modulação", de sorte "que ela forma um sentido agradável ao ouvido; a melodia vocal se chama canto; e a instrumental, sinfonia". . No Ensaio, a sinfonia não tem lugar nas reflexões sobre a língua primeva, mas sim a melodia vocal, o canto. Em suma, é a voz humana o elemento a ser considerado.

Posto isto, inversamente ao que um leitor desavisado poderia pensar, é notório que o Ensaio não reúne duas matérias distintas. O livro não aproxima dois temas diversos e heterogêneos, mas, ao contrário, música e língua participam de um duplo movimento na obra de Rousseau, a saber: descrevem uma gênese única e constituem uma única e mesma estrutura. De acordo com as palavras de Bento Prado Júnior,

a música ocupa, de fato, um lugar central na economia do Ensaio: ela se encontra, ao mesmo tempo, no ponto de partida da gênese ideal e em um

\footnotetext{
5 VALÉRY, Introduction à la Méthode de L. de Vinci, p. 44.

${ }^{6}$ ROUSSEAU, Lettre à M. Burney et fragments d'observations sur l'Alceste de Gluck, OC, V, p. 445.

${ }^{7}$ ROUSSEAU, Essai sur l'origine des langues, OC, V, p. 381.

8 ROUSSEAU, Essai sur l'origine des langues, OC, V, p. 410.

${ }_{9}$ ROUSSEAU, Dictionnaire de musique, OC, V, p. 884.
} 
dos polos da reflexão sistemática. [...] Em sua ubiquidade, ao longo do Ensaio, a música se apresenta como o paradigma segundo o qual a história e a essência da linguagem são pensadas ${ }^{10}$.

Kintzler possui uma interpretação semelhante: "não somente música e língua derivam da mesma fonte, não somente elas são da mesma natureza, mas, ainda, uma é redutível à outra" ". Para desvendar as implicações da relação entre língua e música, não é de todo fora de propósito demorarmo-nos na análise da ideia de acento. Com ela, entramos no coração do sistema linguístico desenvolvido por Rousseau, já que o acento é justamente o princípio ou o elo sobre o qual o autor estabelece a indistinção inicial e originária entre língua e música. No verbete "Melodia" do Dicionário de música, notamos que a presença do acento em uma determinada língua é o elemento responsável por fazer com que ela seja própria para a música. Se existe acento, a língua convém à música. Ou seja, ele determina o caráter vivo, melodioso e rítmico de uma língua; em contrapartida, sua ausência faz com que a língua tenha uma melodia fria, monótona e estéril ${ }^{12}$. No verbete dedicado ao termo, Rousseau caracteriza o acento como "a semente de toda música", sendo "a maior ou menor recorrência do acento a verdadeira causa que deixa as línguas mais ou menos musicais" 13 .

Definir o que é o acento, todavia, não é tarefa fácil. Tal definição figura apenas de forma insatisfatória nas páginas do Ensaio, pois por mais que apareça em quase todos os principais momentos e que se reconheça sua importância para a teoria da linguagem, o acento ainda é um conceito que aí permanece pouco esclarecido e jamais se deixa deduzir a uma acepção simples. Faz-se, então, necessário recorrer a outros textos do autor. No Dicionário de música, por exemplo, Rousseau define o acento como a modificação qualitativa e quantitativa da voz falante:

toda modificação da voz falante na duração ou no tom das sílabas e das palavras pelas quais o discurso é composto; isso mostra uma relação muito exata entre os dois usos dos Acentos e as duas partes da Melodia, a saber, o Ritmo e a Entonação ${ }^{14}$.

O acento introduz o fracionamento da duração e a modificação da altura do som. Em outras palavras, ele é a modificação da voz falante na duração e no tom, culminando em uma voz cantante, o elemento que faz da fala uma música, do discurso uma canção.

A partir dessa definição podemos indagar qual função o acento ocupa na economia do Ensaio. Aos olhos de Rousseau, os primeiros sons emitidos pelos homens foram convenientes aos sentimentos vivenciados, derivam diretamente das paixões. Tal como sugere Horácio nas páginas da Arte poética - ao refletir sobre a construção de um personagem o autor precisa cuidar para que seja garantida a conveniência que a ação desse personagem

10 PRADO JÚNIOR, A retórica de Rousseau e outros ensaios, pp. 152-153.

11 KINTZLER, Rameau et Rousseau: le choc de deux esthétiques, p. XXXII.

12 ROUSSEAU, Dictionnaire de musique, OC, V, p. 885.

${ }^{13}$ ROUSSEAU, Dictionnaire de musique, OC, V, p. 614.

14 ROUSSEAU, Dictionnaire de musique, OC, V, pp. 613-614. 
deve ter em relação à sua idade ${ }^{15}$ - também aqui, em Rousseau, cada tipo de sentimento e de paixão deve possuir um determinado acento que lhe seja conveniente. "Os acentos são mais frequentes ou mais raros, as inflexões mais ou menos agudas, segundo o sentimento que a eles se liga", nos diz o Ensaio ${ }^{16}$. Para evidenciar isso, o autor elenca vários exemplos: não existe nenhum homem no mundo, demasiadamente frio e desprovido de sentimento, para dizer coisas apaixonadas sem jamais adocicar ou reforçar a voz ${ }^{17}$; "para comover um jovem coração, para repelir um agressor injusto, a natureza dita acentos, gritos, lamentos"18; ou ainda, "as paixões têm seus gestos, mas elas também têm seus acentos" e esses acentos "nos fazem tremer" 19 .

Os acentos funcionam na teoria da linguagem de Rousseau como o meio pelo qual as inflexões de vOz são moduladas em função do gênero de paixão ou sentimento que se experimenta e que se exprime àqueles que escutam. Aos olhos do autor, servem fundamentalmente para comover e emocionar outra pessoa a partir de uma emoção ou comoção previamente experimentada pelo emissor, sendo o elo entre duas paixões: uma do emissor e outra do ouvinte. De acordo com a teoria apresentada, as inflexões de voz penetram no fundo dos corações dos ouvintes portando movimentos análogos às paixões que os arrancaram do emissor. Tais movimentos fazem com que os ouvintes sintam aquilo que ouviram, sem que seja necessário articular um sentido às palavras. Não por acaso SaintPreux define na carta XLVIII da primeira parte da Nova Heloísa "o acento oratório e patético" como "a arte de falar ao ouvido e ao coração em uma língua que não articula as palavras"20. Nesses termos, a concepção de linguagem de Rousseau "toma aqui o estado puro da palavra cantada" 21; acompanha o próprio movimento da emoção; não se contentando em exprimilo, é sua parte integrante já que os acentos e as vibrações da voz nascem diretamente das paixões e podem evocar nos ouvintes paixões idênticas às primeiras, isto é, idênticas àquelas que os fizeram nascer. Isto mostra porque o sentimento é transmitido tão fidedignamente: "o acento", nos diz o Emílio, "mente menos que a palavra"22.

De acordo com essa teoria, os acentos possuem uma relação íntima com os sentimentos e as paixões, de sorte que não nos surpreendemos quando Rousseau afirma que o Crátilo de Platão não é tão absurdo e ridículo quanto possa parecer ${ }^{23}$. $\mathrm{O}$ acento das paixões que oferece à linguagem original suas primeiras palavras imitativas não está de forma alguma separado dessas paixões: "ele é o signo mal representativo; ele é antes o índice, ou seja, o

15 "Os anos, à medida que vêm, trazem consigo vantagens sem número; à medida que se vão, levam consigo um sem-número delas. Não se atribua a um jovem o quinhão da velhice, nem a um menino o dum adulto; a personagem manterá sempre o feitio próprio e conveniente a cada quadra da vida" (HORÁCIO, Arte Poética, p. 60).

${ }^{16}$ ROUSSEAU, Essai sur l'origine des langues, OC, V, p. 410.

17 ROUSSEAU, Examen de deux principes avancés par M. Rameau, OC, V, p. 357. A mesma passagem pode ser encontrada, com algumas variantes, no texto Princípio da melodia ou resposta aos erros sobre a música (ROUSSEAU, Du Principe de la mélodie, pp. 454-455).

18 ROUSSEAU, Essai sur l'origine des langues, OC, V, p. 380.

${ }^{19}$ ROUSSEAU, Essai sur l'origine des langues, OC, V, p. 378.

${ }^{20}$ ROUSSEAU, Julie ou la nouvelle Héloïse, OC, II, p. 133.

${ }^{21}$ LEFEBVRE, L'esthetique de Rousseau, p. 21.

22 ROUSSEAU, Émile ou de l'éducation, OC, IV, p. 296.

${ }^{23}$ ROUSSEAU, Essai sur l'origine des langues, OC, V, p. 383. 
sintoma" 24 . Desse modo, os acentos não estão ligados às paixões por meio de uma relação representativa. A arbitrariedade convencionalista da função representativa da linguagem - de acordo com a qual certos sons representam determinadas ideias por convenção - é colocada de lado nesse momento das reflexões de Rousseau. Como bem notou André Wyss:

no começo (do homem; extrapolemos: da humanidade) não é o sentido que faz o objeto da comunicação, mas o "acento", ou seja, é possível que a "primeira palavra" tenha um significado, mas isso não pode ser outra coisa senão aquilo que sugere a maneira de dizer; em suma, o acento antecedeu o sentido, e se houvesse em seguida um sentido, ele não faria senão suprir um acento que desapareceu. [Rousseau] situa o "acento" não somente no coração do significante, mas no lugar do significado, no momento original em que o signo ainda não está dividido em "significante" e "significado", no momento em que a expressão, simples "acento", é o índice da paixão que comunica (melhor: que traduz), no momento em que a expressão não está ainda separada do referente, portanto, onde o signo como tal, stricto sensu, não existe! $!^{25}$

Uma interpretação análoga pode ser encontrada em Starobinski:

no início, a palavra não é ainda o sinal convencional do sentimento; é o próprio sentimento. Transmite a paixão sem transcrevê-la. A palavra não é um parecer distinto do ser que designa: a linguagem original é aquela em que o sentimento aparece imediatamente como é, em que a essência do sentimento e o som proferido são uma e mesma coisa. Rousseau não esquece de mencionar o Crátilo de Platão, pois sua descrição da primeira língua não faz mais que retomar, aplicando-a à paixão e ao sentimento, a hipótese das "denominações naturais" e dos "nomes primitivos": "O nome contém por natureza uma certa retidão". ${ }^{26}$

O substancial de uma língua - e é justamente isso o que interessa - está nos tons e nos ritmos, nas vibrações e inflexões da voz, isto é, na cadência dos acentos ou na musicalidade da fala. Não se trata do sentido ou do significado das palavras. Em um primeiro patamar elevam-se a língua musicada pelos acentos e seus efeitos sobre as pessoas, ou seja, sua força evocativa. Em certa medida e mesmo que sejam - ou tenham se tornado representativas, as línguas históricas ainda guardam, umas mais do que outras, certos resquícios da língua originária. As línguas orientais possuem maiores proximidades com a língua original do que as línguas modernas europeias. Não à toa Rousseau afirma que "toda sua força está nos acentos" ${ }^{\prime 2}$.

${ }^{24}$ WYSS, Jean-Jacques Rousseau: l'accent de l'ecriture, p. 26.

25 WYSS, Jean-Jacques Rousseau: l'accent de l'écriture, p. 28.

${ }^{26}$ STAROBINSKI, Jean-Jacques Rousseau: a transparência e o obstáculo, p. 155.

${ }^{27}$ ROUSSEAU, Essai sur l'origine des langues, OC, V, p. 409. 


\section{" $O$ canto tornou-se gradativamente uma arte inteiramente separada da língua" 28}

Depois de pintar o retrato da língua primeva, o autor apresenta os elementos que contribuem para a degeneração das línguas: o excesso de consoantes e de articulações, a harmonização, o desvanecimento da imitação musical, a invenção da escrita, os desenvolvimentos da razão, os aperfeiçoamentos técnico-cognitivos e as alterações históricas, sociais, econômicas e políticas.

No início, as línguas não eram nem metódicas nem razoadas, quase não possuiriam articulações, apenas "algumas consoantes interpostas, apagando o hiato das vogais". A sentença de Rousseau é taxativa: "O acento se extingue e a articulação se estende" 29 . A presença de articulações é um índice seguro dos processos de racionalização e de desenvolvimento sofridos por uma língua, pois são difíceis de serem produzidas sem o auxílio de exercícios e do aprendizado. Acerca dessa convencionalidade das articulações, em oposição aos acentos (naturais e espontâneos), o início do capítulo IV do Ensaio é particularmente instrutivo:

os sons simples saem naturalmente da garganta, permanecendo a boca naturalmente mais ou menos aberta; mas as modificações da língua e do palato que faz̧em articular exigem atenção, exercício; não se as faz sem o querer; todas as crianças têm necessidade de aprendê-las e várias não o conseguem facilmente. ${ }^{30}$

O Ensaio apresenta uma oposição entre dois elementos, um original (o acento) e outro que vem em seu encalço, querendo roubar seu lugar, a saber, a articulação. $O$ autor indica que

quem quer que estude a história e o progresso das línguas verá que mais monótonas se tornam as vozes, mais as consoantes se multiplicam e que aos acentos que desaparecem, as quantidades que se igualam são substituídas por combinações gramaticais e por novas articulações. [...] À medida que as necessidades crescem, os negócios se complicam, as luzes se expandem, a língua muda de caráter. Torna-se mais justa e menos apaixonada, substitui os sentimentos pelas ideias, não fala mais ao coração, mas à razão. ${ }^{31}$

A articulação tende a deslocar ou substituir a espontaneidade da vocalização e, por isso, no decorrer da história, a energia do acento acaba por se perder. Crivadas por elementos

\footnotetext{
28 ROUSSEAU, Du Principe de la mélodie, p. 461.

${ }^{29}$ ROUSSEAU, Essai sur l'origine des langues, OC, V, p. 384.

30 ROUSSEAU, Essai sur l'origine des langues, OC, V, p. 382 (grifo nosso).

${ }^{31}$ ROUSSEAU, Essai sur l'origine des langues, OC, V, p. 384.
} 
convencionais (consoantes mudas e articulações), as línguas tendem a perder suas inflexões acentuadas no decorrer da história, tornando suas vogais monótonas e apagadas. Com a introdução de elementos consonantais, a língua deixa de ser musical, o que representa uma degeneração.

A música segue um caminho não muito diferente. A voz cantante e apaixonada é substituída por um sistema de sons considerados apenas em suas propriedades físicas - eis o processo de harmonização ${ }^{32}$. Paulatinamente, ela perde sua melodicidade, passando a se orientar por outros princípios, buscando, doravante, agir fisicamente sobre as sensações. Para Rousseau, a corrupção da música corresponde ao apagamento de sua potência expressiva e de sua moralidade, refere-se a uma autonomização e proeminência da harmonia artificial raciocinada e, por isso, inexpressiva - sobre a melodia. A harmonização é outro elemento, mais um dos mobilizados por Rousseau, responsável pela degeneração da língua musical original. Enquanto as línguas se articulam, a música se harmoniza. A harmonização é para a música o que a articulação é para a língua vocálica. Eis, dirá Rousseau,

como o canto tornou-se gradativamente uma arte inteiramente separada da língua da qual ela se origina; como o sentimento do som e de seus harmônicos fê-lo perder aquele do acento oral, da quantidade numérica e, por conseguinte, da medida e do ritmo; e como, enfim, limitada ao efeito puramente físico do concurso das vibrações, a música se encontrou totalmente desprovida dos efeitos morais que ela havia produzido quando era duplamente a vOz da natureza. ${ }^{33}$

No fim das contas, as palavras se separam da música, tornando-se estrangeiras uma em relação à outra, tal como evocara Valéry; perdem a característica de expressar as paixões e o mundo moral. Língua e música pouco a pouco se tornam complicadas e degradadas, as vozes se silenciam em uma surda monotonia e os acentos desaparecem, acarretando a perda da expressividade no campo linguístico-musical.

Outros fatores entram em jogo e corroboram para o apagamento da expressividade. Rousseau fala de um progressivo aperfeiçoamento da escrita e a consequente preeminência desta sobre a fala, o que acarreta mudanças na natureza e no estatuto das línguas. O ponto nevrálgico da argumentação é o seguinte: quando a arte de escrever começa a ser praticada, há uma mudança, uma alteração na língua, uma degeneração. Por isso, devem "todas as línguas letradas, por um progresso natural, mudar de caráter e perder força, ganhando clareza" ${ }^{34}$; ou ainda, "a escrita, que parece dever fixar a língua, é justamente o que a altera; não lhe muda as palavras, mas o gênio" 35 . Em outras palavras, a preponderância da escrita

32 Toda essa discussão nos leva diretamente ao debate musical entre Rousseau e o renomado compositor de Dijon, Jean-Philippe Rameau (1683-1764). O leitor desejoso de obter mais informações sobre as relações entre Rousseau e Rameau não pode deixar de consultar o trabalho de Fábio Yasoshima (Entre o canto das paixões e os artifícios da harmonia: o pensamento musical de Rousseau contra o sistema harmônico de Rameau).

${ }^{33}$ ROUSSEAU, Du Principe de la mélodie, p. 461.

${ }^{34}$ ROUSSEAU, Essai sur l'origine des langues, OC, V, p. 392.

${ }^{35}$ ROUSSEAU, Essai sur l'origine des langues, OC, V, p. 388. 
numa língua é índice de sua clareza e de sua complexidade lógico-gramatical às expensas de sua força expressiva. Se ela desempenha satisfatoriamente sua função por sua clareza, não serve mais para emocionar ou comover alguém, não pode mais exprimir os sentimentos, nem tem mais um "uso na vida civil" 36 . O exercício da escrita provoca o enfraquecimento da palavra cantada. As línguas alteradas pela escrita e pelo aperfeiçoamento da sintaxe cessam de ser musicais e perdem sua eloquência originária. O que promove a desqualificação da escrita é a atonia ou a homogeneidade dos signos visuais. Ou seja, a desqualificação se funda na incapacidade da escrita em garantir a essência da fala quando da sua transcrição fonética. A escrita impõe uma monotonia às línguas.

As mudanças que se impõem às línguas refletem também modificações na esfera político-social. $\mathrm{O}$ autor estabelece uma correlação entre desenvolvimento da língua e processos sociais, econômicos e políticos.

Nos tempos antigos, em que a persuasão servia de força pública, a eloquência era necessária. De que serviria ela hoje, quando a força pública substituiu a persuasão? Não se precisa de artifícios nem de figuras de estilo para dizer: esta é a minha vontade. Que discursos restam a fazer, portanto, ao povo reunido? Sermões. E que importa àqueles que os fazem se estão persuadindo o povo, visto que não é ele que distribui os benefícios? As línguas populares tornaram-se tão perfeitamente inúteis quanto a eloquência. As sociedades adquiriram sua última forma: nelas só se transforma algo com artilharia ou escudos; e como nada mais se tem a dizer ao povo, a não ser dai dinheiro, dizemo-lo com cartazes nas esquinas ou com soldados dentro das casas. Não se deve reunir ninguém para isso; pelo contrário, é preciso manter as pessoas separadas; eis a primeira máxima da política moderna. ${ }^{37}$

As línguas - bem como os homens - estão profundamente atreladas ao tempo e, por conseguinte, em constantes transformações. Elas seguem "as vicissitudes dos costumes e se altera $[\mathrm{m}]$ ou se conserva[m] com eles", escreve Rousseau nas páginas do Emílio ${ }^{38}$. Citando Charles Duclos (Comentários sobre a Gramática geral e razoada de Port-Royal, 1754) no final do Ensaio, o autor afirma que "o caráter, os costumes e os interesses de um povo têm influência sobre sua língua" 39 . Trata-se de um processo perfeitamente natural ${ }^{40}$. Assim, da mesma maneira que as necessidades que promoveram o nascimento da sociedade correspondem à emergência das palavras, o declínio social - a transformação dessas mesmas necessidades corresponde a uma depravação linguística ${ }^{41}$.

36 ROUSSEAU, Prononciation, OC, II, p. 1249.

${ }^{37}$ ROUSSEAU, Essai sur l'origine des langues, OC, V, p. 428.

38 ROUSSEAU, Émile ou de l'education, OC, IV, p. 346.

39 ROUSSEAU, Essai sur l'origine des langues, OC, V, p. 429; DUCLOS, Remarques sur la grammaire générale et raisonnée, p. 11. O leitor interessado em desvendar as relações entre Rousseau e Duclos poderá recorrer ao artigo de Lucas Ribeiro ("Linguagem e política: Rousseau leitor de Charles Duclos").

${ }^{40}$ ROUSSEAU, Essai sur l'origine des langues, OC, V, p. 384.

${ }^{41}$ ROUSSEAU, Essai sur l'origine des langues, OC, V, p. 428. 
Se, por um lado, as transformações linguísticas acompanham a corrupção política e social, por outro, os costumes, os governos e as sociedades também se alteram com as mudanças nas línguas. "É impossível que um povo permaneça livre e fale uma tal língua", diz-nos o Ensaio ${ }^{42}$. Língua e sociedade participam de um jogo de mútua determinação em que uma reflete a outra e uma age sobre a outra. Por isso é possível dizer que a marcha evolutiva das línguas se confunde com as etapas da socialização, mantém relações estreitas com os diversos modos de subsistência e de produção dos povos.

No capítulo final do Ensaio, Rousseau pontua o caráter propriamente político da eloquência nos tempos antigos e seu não lugar nas sociedades ocidentais modernas. As línguas antigas - Rousseau elogia sobremaneira a música grega e seus extraordinários poderes ao longo do capítulo XII -, extremamente acentuadas e imbuídas de um caráter público, eram próprias para ser utilizadas a céu aberto e bastante convenientes para uma República, pois levavam ao longe: "entre os antigos", afirma o cidadão de Genebra, "podia-se ser ouvido com facilidade na praça pública; falava-se um dia inteiro sem grande incômodo. Os generais arengavam suas tropas, eram ouvidos e de modo algum se esgotavam" ${ }^{43}$. Estas línguas diferiam profundamente das modernas (ocidentais), adequadas somente aos ambientes fechados e restritos, mais íntimas e menos populares. Referindo-se a seus contemporâneos, o autor afirma no Contrato social que "a praça pública não é suportável" e que suas "línguas insonoras não podem fazer-se ouvir ao ar livre" 44 . No Ensaio, Rousseau segue as reflexões de Duclos, segundo o qual as línguas modernas se tornaram insensivelmente mais adequadas "à conversação do que à tribuna" ${ }^{45}$. Podemos também citar Condillac, outra grande influência - ao lado de Duclos - para Rousseau nesse domínio. O elogio do caráter público das línguas antigas, em contraposição ao caráter privado das modernas, é apresentado por Condillac em seu Ensaio sobre a origem dos conhecimentos humanos (1746): percebo ainda, diz o abade,

na prosódia dos antigos, a razão de um fato que ninguém, creio eu, tenha explicado. Trata-se de saber como os oradores romanos, que arengavam na praça pública, podiam ser ouvidos por todo o povo. Os sons de nossa voz chegam facilmente às extremidades de uma praça de grande extensão; toda a dificuldade é impedir que os confundamos. Mas esta dificuldade deve ser menor na proporção que, pelo caráter da prosódia de uma língua, as sílabas de cada palavra se distinguem de maneira mais sensível. No latim, elas diferiam pela qualidade do som, pelo acento que, independentemente do sentido, exigia que a voz se elevasse ou se abaixasse, e pela quantidade; faltamnos acentos, nossa língua praticamente não possui quantidade, e muitas de nossas sílabas são mudas. Um romano podia, então, se fazer compreender distintamente em uma praça onde um francês não o poderia senão dificilmente ou, talvez, de maneira nenhuma. ${ }^{46}$

42 ROUSSEAU, Essai sur l'origine des langues, OC, V, p. 429.

43 ROUSSEAU, Essai sur l'origine des langues, OC, V, p. 428.

44 ROUSSEAU, Du Contract social, OC, III, p. 43.

45 DUCLOS, Remarques sur la grammaire générale et raisonnée, p. 10.

46 CONDILLAC, Essai sur l'origine des connaissances bumaines, pp. 217-218. O leitor interessado em compreender as relações entre Rousseau e Condillac no que diz respeito à questão aqui posta poderá 
Grosso modo, existia nos tempos antigos uma força de convencimento da fala oriunda dos poderes dos acentos presentes na língua. Ademais, a participação ativa em uma República supunha uma língua viva e acentuada, exigia a capacidade oratória e o uso público da linguagem, pois só assim o cidadão poderia participar ativamente do corpo político, tendo em vista garantir o bom andamento dos assuntos comuns. Mas quando a sociedade atinge "sua última forma", não se deve mais reunir os cidadãos para que decidam conjuntamente os rumos da cidade. Cabe, antes, separá-los e, neste caso, a surdez da língua, sua carência de acentos e de força expressiva, longe de configurarem um defeito, são elementos bastante convenientes. Essa última forma da sociedade não condiz mais com uma língua acentuada. Neste estágio, ao contrário, o próprio imperativo escrito e colocado nas placas, "dai dinheiro" (donnez de l'argent), oblitera os imperativos orais originais: aimez-moi (amai-me) ou aidez-moi (ajudai-me).

Em resumo, após ter evocado o surgimento e as características das primeiras palavras, Rousseau descreve a história progressiva e irreversível de uma corrupção. As línguas perdem sua força, suas entonações e suas inflexões; tornam-se lógicas, frias e monótonas, afastandose do modelo originário. A música, por seu turno, caminha para um fim parecido: sua melodia desvanece em virtude dos progressos da harmonia e da valorização das relações físicas sobre as morais. A poesia, por fim, confinada à escrita, perde o poder soberano de que gozava quando não passava de linguagem oral. Se o movimento da linguagem reproduz, a seu modo e em seu plano, o da humanidade, eis então o fim da história e o fim do discurso, o momento preciso em que as histórias da sociedade e da língua caem no estágio máximo de corrupção. Eis a gênese da linguagem e sua posterior degeneração.

O ponto final do Ensaio sobre a origem das linguas, em que "as sociedades adquiriram sua última forma" se harmoniza perfeitamente com a conclusão do Discurso sobre a desigualdade, isto é, com o último grau de desigualdade representado pelo estado formado por senhor e escravos:

É este o último termo da desigualdade, o ponto extremo que fecha o círculo e toca o ponto de que partimos; é nele que todos os particulares voltam a ser iguais porque nada são, e que, já não tendo os súditos outra lei além da vontade do senhor, nem o senhor outra regra além das suas paixões, se esvaem mais uma vez as noções do bem e os princípios da justiça. É nele que tudo se resume apenas à lei do mais forte e, por conseguinte, a um novo estado de natureza diferente daquele por que começamos. ${ }^{47}$

Ambos os livros apresentam a massa amorfa de súditos escravizados sendo controlada pelo monstro do absolutismo centralizador. Se o Discurso sobre a desigualdade

consultar os trabalhos de Evaldo Becker (Politica e linguagem em Roussean e "Política e linguagem em Rousseau e Condillac").

${ }^{47}$ ROUSSEAU, Discours sur l'origine de l'inégalité, OC, III, p. 191. 
termina com um novo estado de natureza diferente daquele pelo qual se começou, o Ensaio desemboca em um novo silêncio, diferente daquele que antecedeu a eclosão das palavras ${ }^{48}$.

Diz o Dicionário de música que nenhuma língua é perfeitamente musical ${ }^{49}$, o que sugere que todas as línguas, sem exceção, sofrem uma degradação ou são resultado de uma degradação. Mesmo se considerarmos que o fim será o mesmo para todas as línguas, podemos pensar em graus de proximidade ou afastamento em relação ao modelo originário traçado. Cada língua atual ocuparia uma posição em uma escala, sendo a italiana melhor posicionada em relação a este modelo do que a língua francesa e pior posicionada se se levar em consideração outras línguas, presentes e passadas. Numa perspectiva de história de longa duração, a língua italiana quando comparada com as línguas orientais ou a grega antiga apresenta maiores traços de corrupção e de degeneração.

Convém indagar então a direção e o sentido assumidos pela história. Aos olhos de Rousseau, bem notou Maria das Graças de Souza, a história humana se apresenta enquanto a história da queda, da corrupção e da degeneração. De acordo com a intérprete, os temas do declínio, degeneração, degradação e corrupção dos povos estão presentes desde o início da carreira literária de Rousseau, ou seja, desde o Discurso sobre as ciências e as artes ${ }^{50}$. Nos dizeres do autor, "nossas almas corromperam-se na medida em que nossas ciências e nossas artes avançaram em direção à sua perfeição" "51. Uma história da queda que vai da pureza primitiva, antiga e selvagem à depravação atual, moderna e civilizada. De um lado, estaria a natureza humana pura, original e primitiva, de outro, a natureza maculada, degenerada e corrupta. A história dessa degeneração seria propriamente a marca da humanidade e seu traço sobre a natureza. As duas frases que abrem o livro I do Emílio ilustram bem isso: "tudo está bem saindo das mãos do Autor das coisas" e, em seguida, "tudo degenera entre as mãos dos homens" ${ }^{\prime \prime}$.

A intenção declarada e a obsessão de Rousseau são precisamente falar da origem. No fundo da multiplicidade e da variabilidade humanas existentes esconde-se uma identidade de origem, um tipo estático originário, uma natureza humana fixa que, paulatinamente, corromper-se-ia. Em seus escritos, Rousseau procura a todo momento uma origem única e absoluta que paulatinamente se degeneraria até atingir o estágio da tirania (último grau da desigualdade). Daí porque é possível falar em uma lógica de tipo primitivo-defletivo, da qual, para corroborar esta leitura, o início dos Diálogos faz referência ${ }^{53}$.

As línguas não escapam desta historicidade, de sorte que o desenvolvimento da linguagem é coextensivo em seu modo e em seu plano ao da humanidade. Por isso, também é viável e até mesmo desejável ler os textos linguístico-musicais de Rousseau de forma semelhante, já que o mesmo processo de degeneração aparece nestes escritos: de um lado, haveria um tipo primitivo e originário de língua e, de outro, a(s) história(s) das alterações e

\footnotetext{
${ }^{48}$ É possível ler a mesma temática do silêncio nas páginas do Contrato social. Assim como acontece no Ensaio, existe no Contrato um movimento de passagem entre dois silêncios: um saudável e necessário para o bom andamento das coisas públicas e outro nefasto, já que imposto por um governo despótico.

49 ROUSSEAU, Dictionnaire de musique, OC, V, p. 615.

50 SOUZA, Ilustração e história, p. 53.

${ }^{51}$ ROUSSEAU, Discours sur les sciences et les arts, OC, III, p. 9.

52 ROUSSEAU, Émile on de l'éducation, OC, IV, p. 245.

${ }^{53}$ ROUSSEAU, Roussean juge de Jean-Jacques: Dialogues, OC, I, pp. 668-669.
} 
dos desvios, a degeneração e corrupção do modelo originário. Assim, depois de Rousseau ter detalhado a natureza e os elementos distintivos da língua patética e acentuada dos primeiros tempos, de duração meramente ficcional, descobrimos que as línguas reais se afastam cada vez mais deste ideal em virtude das transformações históricas, sociais, econômicas e políticas, bem como do apagamento de sua força expressiva e do desaparecimento do acento oratório em prol de clareza e exatidão designativas.

A história da queda vale também para as línguas. As reflexões linguístico-musicais também operam na lógica binária do tipo primitivo e do seu correlato defletivo. Há uma língua originária que se degenera e se altera: um processo de formação do tipo ideal e uma deformação. De um passado originário, ficcional ou mítico das línguas chegamos à existência atual, afastada em todo caso do tipo primeiro; de uma identidade primeira desembocamos numa variedade atual.

\section{"Tudo isso não será indistintamente verdadeiro"54}

O próprio Rousseau coloca um sério problema para a leitura de tipo primitivodefletivo, a saber: é impossível traçar uma gênese única para a origem das línguas, bem como, de modo mais geral, para o homem e a cultura. Por isso, o autor estabelece uma distinção entre povos do norte e povos do sul, entre uma origem setentrional e outra meridional para as línguas. As primeiras são, sobretudo, línguas da necessidade, ao passo que as últimas, às quais Rousseau proporciona dez vezes mais espaço em sua descrição, são línguas da paixão.

No que diz respeito às questões linguísticas e antropológicas, a aparição originária da língua fria e articulada e do homem setentrional dificulta a validade da chave interpretativa de tipo primitivo-defletivo, já que eles não podem ser considerados apenas como uma língua e um homem corrompidos - diga-se de passagem, que já nascem corrompidos -, sob o risco de pensarmos que a antropologia de Rousseau resolve-se inteiramente num modelo no qual somente em determinadas regiões geográficas o homem poderá ser verdadeira e efetivamente homem (os homens do sul) e somente alguns lugares seriam favoráveis à boa expressão cultural (as línguas e as músicas do sul). É possível dizer então que Rousseau manifesta exatamente aquilo que ele mais denunciou em seus escritos, a saber, o etnocentrismo? Longe de refletir perspectivas etnocêntricas, a revolução antropológica de Rousseau, aclamada por tantos autores e celebrada por Lévi-Strauss, está em sustentar a ideia de que uma cultura não pode se afirmar como a única verdadeira e digna de ser vivida, ignorando as outras ou negando a elas o estatuto de culturas (diversas e diferentes). Para Rousseau, há culturas no plural e é preciso levar a sério esta pluralidade.

Isso não significa descartar pura e simplesmente a leitura de tipo primitivo-defletivo. Ela terá seu lugar preservado no quadro da reflexão de Rousseau, contudo permanecerá dentro de certos limites e não poderá ser generalizada. A partir de agora, nosso objeto será explicar a impossibilidade de se falar em uma origem única, bem como sistematizar o quadro no interior do qual a leitura de tipo primitivo-defletivo deverá ser utilizada.

${ }^{54}$ ROUSSEAU, Essai sur l'origine des langues, OC, V, p. 381. 
Existem duas teses opostas no livro: uma que supõe as paixões como a origem única das línguas e outra que afirma as necessidades e as paixões enquanto representantes de duas origens que se opõem mutuamente. Normalmente e de acordo com a descrição realizada nos primeiros capítulos do Ensaio, a necessidade separa os homens em vez de aproximá-los. No Norte, ao contrário, ela é a origem da sociedade e da palavra. A afirmação de que as línguas do Norte são línguas da necessidade parecem contradizer as declarações do próprio autor, presentes no segundo capítulo do Ensaio e de acordo com as quais é excluída a hipótese da língua nascer da pura necessidade ${ }^{55}$.

Os sete primeiros capítulos representam a primeira tese e tratam da língua em sua generalidade, porém eles não representam a totalidade do texto, não ocupam toda sua economia. É por isso que se pode discernir uma descontinuidade marcada por duas lógicas heterogêneas: em primeiro lugar aquela dos capítulos I a VII que retraça a evolução das línguas desde sua origem única até seu estado atual, lógica que tem seu paralelo nos capítulos concernentes à evolução e à degradação da música (do XII ao XIX); já a outra lógica é aquela dos capítulos VIII a XI que representa a segunda tese e explica a diversidade das línguas a partir da diversidade de origens, da diferença dos climas, dos terrenos e dos processos de socialização dos homens. O problema central daí decorrente é que esses novos desenvolvimentos retificam radicalmente aqueles capítulos precedentes. No entanto, a contradição apenas existe se pensarmos em uma origem única. Todo e qualquer descompasso desaparece se considerarmos uma multiplicidade de origens possíveis.

A passagem de uma estrutura de origem monolítica ou unitária para uma estrutura dualista (Norte e Sul) ou mesmo pluralista não se dá por uma continuidade entre elas, mas tão somente por meio da noção de "catástrofe" 56 e da postulação de uma história que é essencialmente disruptiva. De onde se segue que um fato exterior, irracional, catastrófico deve irromper para produzir o estreitamento das relações sociais e, consequentemente, a dupla ou a plural origem das línguas. Sem essa noção não haveria senão uma única genealogia. Assim, a catástrofe faz com que a homogeneidade da primavera perpétua da idade de ouro - o merídio absoluto - não esteja mais presente no globo terrestre. Desse modo, ela insere a diferença espacial e também temporal, alterando a topografia e o clima da Terra.

A homogeneidade é apresentada no capítulo IX: "suponde uma primavera perpétua na Terra; suponde por toda parte água, gado, pastagens; suponde os homens ao saírem das mãos da natureza, e já espalhados por essas regiões" ${ }^{\text {57. }}$. Rousseau descreve um estado présocial no qual não se exige nenhum esforço para a sobrevivência do gênero humano. Tal paraíso terrestre, que reteve os homens em sua indolência originária, findou com uma espécie de piparote demiúrgico que forçou a união entre eles. Eis a inscrição da catástrofe no seio do Ensaio: aquele que inclinou com o dedo o eixo do globo foi o responsável pela catástrofe e

\footnotetext{
55 O próprio título do segundo capítulo do Ensaio já indica isso: "De como a primeira invenção das palavras não vem das necessidades, mas das paixões" (ROUSSEAU, Essai sur l'origine des langues, OC, V, p. 380).

56 A palavra "catástrofe" é citada apenas uma vez no Ensaio, a saber, no quarto parágrafo do capítulo XIX (ROUSSEAU, Essai sur l'origine des langues, OC, V, p. 425). No entanto, se o termo é pronunciado apenas uma vez, o conceito está rigorosamente presente no Ensaio (DERRIDA, De la Grammatologie, p. 361).

${ }^{57}$ ROUSSEAU, Essai sur l'origine des langues, OC, V, pp. 400-401.
} 
pelo estreitamento dos laços sociais indispensáveis para o surgimento das línguas ${ }^{58}$. Por uma catástrofe circunstancial e contingente - que poderia nunca ter ocorrido -, foi alterada a própria dinâmica e toda a face do globo terrestre fazendo com que mudasse a topografia e, consequentemente, a estrutura para se pensar a origem das línguas. À unidade da primavera perpétua, a catástrofe faz suceder a dualidade ou pluralidade de princípios, a polaridade e a oposição dos lugares, o Norte e o Sul, as revoluções das estações do ano que de alguma forma fazem mudar o clima do mesmo local, produzindo a alternância do quente e do frio, da água e do fogo.

Doravante, a pressão da necessidade varia com o lugar e, de acordo com a força de pressão da necessidade sobre a formação da socialização, teremos que lidar com diferentes tipos de paixões e, por conseguinte, com diferentes origens das línguas. Assim, os agrupamentos localizados nas regiões mais quentes estavam mais próximos da "primavera perpétua" da idade do ouro. Suas línguas devem ser "vivas, sonoras, acentuadas, eloquentes", pois as necessidades materiais são aí mais fáceis de satisfazer e os seres mais disponíveis para a paixão amorosa. Já as regiões frias do Norte, muito mais afastadas dessa primavera, possuem línguas "surdas, rudes, articuladas, gritantes, monótonas e claras" 59 . Suas línguas são mais ásperas, as consoantes mais marcadas, já que os habitantes têm frequentemente mais ocasião de comunicar suas inquietudes e suas dificuldades do que suas alegrias de viver.

Enquanto as línguas do Sul nascem de uma demanda de amor (aimez-moi) já que são as paixões que arrancam as primeiras vozes, as línguas do Norte nascem de uma demanda de ajuda, de um pedido de socorro (aidez-moi). A diferença que reside em um mero traço fonemático é de capital importância: de um lado, um bilabial $(m)$ e, de outro, um dental (d). A agressividade dos homens do Norte necessita de uma articulação consoante mais dura para se expressar, ao passo que as paixões dos homens do Sul são transmitidas com uma linguagem mais melodiosa e mais doce. O toque labial é o mais fácil de acionar, o mais suave e gracioso. Em contrapartida, os dentes são mais firmes e as entonações que deles provêm são fortes e ruidosas. Dizendo de outra maneira, os povos nórdicos necessitam de uma língua da razão para que se façam entender, uma língua que se sobressai pela clareza, mas que, ao mesmo tempo, perde em força expressiva. Já as línguas do Sul são vivas e melodiosas, capazes de exprimir as paixões humanas. Não que os homens do Norte não possuam paixões, eles as têm, mas de uma espécie diferente daquela do Sul, já que a pressão da necessidade sobre a formação da socialização é muito maior.

As diferentes línguas históricas, "centenas de vezes misturadas e refundidas", ainda hoje conservam alguma coisa de suas características constitutivas originais. Em proporções diferentes, elas preservaram algo que remete às suas origens: "o francês, o inglês e o alemão", afirma Rousseau, "são a linguagem privada dos homens que se auxiliam, que raciocinam com sangue frio, ou de pessoas coléricas que brigam”. São fundamentalmente línguas do Norte.

58 ROUSSEAU, Essai sur l'origine des langues, OC, V, p. 401. No texto $A$ influência dos climas sobre a civilização, Rousseau insiste nesta mesma imagem: "Inclinar com o dedo o eixo do mundo ou dizer ao homem: Cobre a Terra e sê sociável, isso foi a mesma coisa para Aquele que não tem necessidade nem de mão para agir nem de voz para falar" (ROUSSEAU, L'influence des climats sur la civilisation, OC, III, p. 531).

${ }^{59}$ ROUSSEAU, Essai sur l'origine des langues, OC, V, p. 409. 
Porém "os ministros dos deuses anunciando os mistérios sagrados, os sábios dando leis ao povo, os chefes arrastando a multidão, devem falar árabe ou persa" ${ }^{60}$, línguas do Sul.

Todas essas passagens indicam que o peso de fatores como o terreno e o clima é nuclear, fazendo-se também notar em outros textos do autor ${ }^{61}$. Os modos como se configuram os processos de socialização, a eclosão das paixões e, por conseguinte, da linguagem, realizam-se a partir de uma relação entre os homens e seu meio ambiente ou suas condições materiais de existência.

Quer, pois, procurando a origem das artes, quer observando os primeiros costumes, vê-se que tudo se liga, em seu princípio, aos meios de atender a subsistência e, no que concerne àqueles meios que reúnem os homens, que são eles determinados pelo clima e pela natureza do solo. Será, pois, pelas mesmas causas que se deve explicar a diversidade das línguas e a oposição de seus caracteres ${ }^{62}$.

Apenas analisando a formação das diferentes sociedades a partir das condições geográficas e climáticas é que se estabelecerá quais paixões correspondem a cada uma delas, o que facilitará a compreensão das diferenças entre as línguas ou entre os acentos. Portanto, convém reconhecer a diferença entre as línguas a partir das diferenças de lugares, das situações geográficas e das condições climáticas que animam os processos de socialização. Os capítulos VIII a XI descrevem que não há nada que se possa denominar língua antes da diferença local.

Tudo o que eu disse até aqui convém às línguas primitivas em geral e aos progressos que resultam de sua duração, mas não explicam nem sua origem nem suas diferenças. A principal causa que as distingue é local, resulta dos climas em que nascem e da maneira pela qual se formam, é a esta causa que é preciso remontar para conceber a diferença geral e característica que se nota entre as línguas do meio e aquelas do norte ${ }^{63}$.

Assim, à diversidade geográfica corresponde uma pluralidade real de modelos de origem para as línguas. Como bem notou Mosconi, Rousseau demonstra que

${ }^{60}$ ROUSSEAU, Essai sur l'origine des langues, OC, V, p. 409.

${ }^{61}$ A influencia dos climas sobre a civilização: "o clima, o solo, o ar, a água, as produções da terra e do mar, formam seu temperamento, seu caráter, determinam seus gostos, suas paixões, seus trabalhos, suas ações de todas as espécies. Se isto não é exatamente verdadeiro nos indivíduos o é incontestavelmente nos povos" (ROUSSEAU, L'influence des climats sur la civilisation, OC, III, p. 530). E também no capítulo VIII do livro III do Contrato social ("Que qualquer forma de governo não convém a qualquer país"): toda uma teoria do excedente da produção do trabalho em relação às necessidades compõe-se nele em sistema com uma tipologia das formas de governo e com uma explicação pelo clima.

${ }^{62}$ ROUSSEAU, Essai sur l'origine des langues, OC, V, p. 400.

${ }^{63}$ ROUSSEAU, Essai sur l'origine des langues, OC, V, p. 394. 
a questão da origem admite somente respostas singulares, que implicam, em cada caso, a análise, sob todos os aspectos, de uma certa relação dos homens com suas condições de existência ${ }^{64}$.

As condições dos homens em relação aos meios de subsistência influenciam diretamente suas trocas mútuas e, consequentemente, a formação das línguas. Essas influências se fazem, no seio de cada sociedade, por meio de um processo singular que só se torna inteligível se referido à análise completa de uma situação histórica, a todos os elementos constitutivos do modo de vida dos homens e, em primeiro lugar, às relações efetivas entre o homem e a natureza.

Não se pode descrever a estrutura das línguas sem levar em conta a topografia e as condições climáticas. No entanto, de forma curiosa, foi justamente isso que Rousseau tentou ou, ao menos, desejou fazer nos sete primeiros capítulos, antes de abordar o capítulo da "diferença geral e local na origem das línguas". Apesar de reconhecer a necessidade de se fazer uma análise topográfica e climatológica, ele parece ter desejado uma origem pura e simples e uma corrupção ou degenerescência dessa origem. Nas palavras de Derrida, Rousseau "gostaria que a origem absoluta fosse um merídio absoluto" 65.

Ainda que seja possível pensar de modo conjectural, portanto, ficcional, em um homem que escape incólume às causas físicas que formam as identidades e as diferenças (um ser puro e neutro, sem cor definida) ou ainda que seja hipoteticamente admissível ter um acesso à coisa em si (à língua pura e originária), é preciso a todo momento admitir que diversas causas agem continuamente para variar a constituição humana e produzir toda a multiplicidade observada nos costumes, regimes alimentares, paixões, línguas, modos de vida, etc. O processo de variação começa no exato momento em que o homem se encontra no mundo.

O esquema de Rousseau é relativamente simples. 1) associam-se à língua primeva (o mesmo pode ser dito do homem do puro estado de natureza apresentado no Discurso sobre a desigualdade) certas condições materiais de existência. As variedades humanas e distinções culturais (dentre elas as variações linguístico-musicais) não são apresentadas no quadro teórico-fictício dos homens dos começos, pois eles hipoteticamente viveriam todos em condições bastante homogêneas. Sendo as condições em todos os lugares as mesmas, por conseguinte, elas produzem homens e culturas homogêneos. 2) às variedades linguísticas encontradas (o mesmo pode ser dito da variedade humana) vinculam-se condições materiais de existência variadas. Como as condições de existência são ou se tornaram distintas em cada rincão da Terra ${ }^{66}$, distintos também são os homens, seus grupos, suas paixões, suas línguas e, em suma, suas culturas.

${ }^{64}$ MOSCONI, "Analyse et genèse: regards sur la théorie du devenir de l'entendement au XVIIIème siècle”, p. 83.

65 DERRIDA, De la Grammatologie, p. 311.

${ }^{66}$ Rousseau analisa no conjunto de sua obra uma série de causas da diversidade física e cultural: o aumento da densidade demográfica, a migração para outros cantos distintos do locus originário de nascimento da humanidade, as ações antrópicas que fizeram variar a superfície terrestre e os climas de cada região, as catástrofes e os acidentes naturais. Se analisamos no presente trabalho apenas a 
O modelo da primeira língua é construído a partir de uma abstração das condições histórico-materiais, ou melhor, a partir da suposição de certas condições materiais de existência bastante precisas, a saber, uma espécie de primavera perpétua. Sendo tais condições materiais alteradas, faz-se necessário pensar em modelos plurais de origem que possam abarcar e explicar a variabilidade e a diferença. Portanto, o discurso único sobre a origem se apaga enquanto tal, interditando considerar o homem e sua língua como algo puro, unívoco e homogêneo.

As condições materiais de existência presentes no modelo ideal fazem-se notar de maneira mais ou menos parcial nas línguas do sul, sublinhando evidentemente que estas já expressam um certo afastamento em relação a ele, por mais ínfimo que seja. No entanto, o que sugere apenas uma diferença de grau entre norte e sul esconde uma diferença de origens. Desse modo, as reflexões de Rousseau indicam que o Norte não é simplesmente o outro distanciado do Sul e das paixões, isto é, ele não é um termo que se atinge partindo-se da única origem concebível, a saber, a meridional. Rousseau reconhece que o Norte é uma outra origem, diferente da origem do Sul, mas tão válida quanto ela. Em relação aos modelos de origens disponíveis que a reflexão antropológica pode acessar, a origem setentrional é, portanto, apenas mais um dos modelos possíveis.

Por isso, é necessário pensar em modelos plurais de origem que possam abarcar e explicar a variabilidade e a diferença em outros termos que não apenas os de degenerescência da única origem concebível. Os esforços de Rousseau se direcionam para apreender as variações e as diferenças linguístico-culturais ou os meios pelos quais cada agrupamento humano inventa a si mesmo, distinguindo-se dos demais, ao perseguir as condições de sua própria existência. Não só não se trata de uma expressão do etnocentrismo, mas de um discurso que vai contra o etnocentrismo. Seu discurso multiplica as origens possíveis, de modo a afirmar a diversidade por ela mesma, sem que a baliza teórica (seja o estado de natureza, seja o homem do puro estado de natureza, seja ainda a língua primeva ou o que quer que seja) tenha lugar ou muita importância. Se na leitura de tipo primitivo-defletivo a diversidade implicava em um discurso sobre a origem e uma primeira alteração que perverteu a origem, ou seja, uma alteração da origem ou origem da alteração, nesse outro modelo de interpretação, por sua vez, a diversidade expressa precisamente a ausência dessa origem, na medida em que um sem-número de outras origens é igualmente possível. Se a origem está em todo lugar, nada é origem. Temos aqui a alteração ou as alterações de origem, originária(s), uma vez que o homem e sua língua deixam de ser pensados a partir do referencial de uma natureza humana e linguística únicas, passando a ser compreendidos apenas a partir dos processos singulares de socialização de cada povo e, mais fundamental, das relações efetivas entre o homem e a natureza.

As alterações e diferenças entre os homens e suas línguas não podem indicar - e as páginas da Gramatologia de Derrida nos ensinaram isso ${ }^{67}$ - pura e exclusivamente a

ideia de catástrofe, em virtude das limitações deste artigo, é preciso todavia levar em consideração todas as outras causas.

67 "Falar de origem e de grau zero é comentar, efetivamente, a intenção declarada de Rousseau e esta corrige a este respeito mais de uma leitura clássica e precipitada. Mas, apesar desta intenção declarada, o discurso de Rousseau se deixa coagir por uma complexidade que tem sempre a forma do suplemento de origem. Sua intenção declarada não é anulada, mas inscrita num sistema que ela já não 
degenerescência de uma natureza fixa, já que não há em Rousseau um quadro único no qual se inscrevem as condições materiais de existência originárias e a partir das quais podemos, de um lado, pensar a língua e o homem da origem e, de outro, o afastamento e o desvio. Ao contrário, a diversidade física e cultural é afirmada enquanto tal, sem que haja a necessidade de se atribuir um prêmio de preservação de uma maior pureza a esta ou aquela sociedade, localizada num ponto determinado do tempo e do espaço. A diversidade indicaria não uma corrupção, mas os vários caminhos assumidos e tomados pelos homens de acordo com os tempos e as circunstâncias.

\section{“É preciso fabricar uma escala" 68}

Constatada a impossibilidade de se traçar uma origem única, por que então Rousseau não descarta o conteúdo dos primeiros capítulos do Ensaio? Por que manter uma concepção de pureza linguística e traçar a história de sua corrupção se o próprio autor admite outras origens possíveis e, como se não bastassem, a observação confirma a existência, de fato, de uma multiplicidade de línguas resultantes de diferentes processos de formação e de socialização? Por que ainda falar de uma origem pura e única da palavra?

O que pretendemos ressaltar é que a chave analítica de tipo primitivo-defletivo ainda tem seu lugar no Ensaio, de maneira que não é possível simplesmente suprimi-la. O modelo de protolinguagem construído hipoteticamente - cujas características marcantes também se encontram em maior grau nas línguas do sul, nas línguas orientais e nas antigas - ainda exerce um papel importante, já que serve como ponto de apoio para a fabricação de uma escala de medida. Assim, o modelo de tipo primitivo-defletivo é atualizado na ideia de escala.

Podemos finalmente retomar o início dessas reflexões e, assim, apontar algumas afinidades envolvendo o Ensaio e o Discurso sobre a desigualdade. Ambos os textos dizem respeito a construções teóricas por meio das quais se realizariam comparações: da mesma forma que o retrato do homem no puro estado de natureza serve como uma tela de fundo sobre a qual, por contraste, as patologias próprias da forma de vida social e moderna se destacam, a língua originária atua como parâmetro comparativo para se medir os graus de afastamento de cada uma das línguas históricas. Ademais, assim como o homem no puro estado de natureza não existe e talvez nunca tenha existido, a língua primeva (perfeitamente musical) não assume um estatuto histórico concreto, talvez jamais tenha realmente existido e nenhuma língua histórica se acomoda plenamente a ela. Independentemente disso, a partir

domina. O desejo da origem torna-se uma função indispensável e indestrutível, mas situada numa sintaxe sem origem. Rousseau desejaria separar a originalidade da suplementariedade. Tem a seu favor todos os direitos constituídos por nosso logos: é impensável e intolerável que o que tem o nome de origem não seja mais do que um ponto situado no sistema da suplementariedade. Esta rouba, com efeito, a língua à sua condição de origem, ao seu condicional ou futuro de origem, ao que ela ter(i)á devido ser e nunca foi: ela só pode nascer ao suspender sua relação com toda a origem. A sua história é a do suplemento de origem: do suplente originário e do suplente da origem" (DERRIDA, De la Grammatologie, p. 345).

${ }^{68}$ ROUSSEAU, Émile on de l'éducation, OC, IV, p. 837. 
do modelo abstrato construído - um instrumento teórico de medida e ordenação - é possível julgar os graus de afastamento ou proximidade das línguas históricas.

O modelo original de explicação do surgimento das línguas não perde validade. Sua manutenção ao longo do Ensaio se justifica já que serve como instrumento de medida capaz de bem conduzir os julgamentos. Para Rousseau, a unificação da música e da língua em um ponto utópico-fictício da origem é o trabalho de um discurso preocupado com o julgamento histórico e com a avaliação do momento presente, das línguas presentes e de suas respectivas sociedades.

Essa avaliação do presente reverbera de forma privilegiada tanto os objetivos do Discurso sobre a desigualdade quanto os do Contrato social. Utilizando a ideia de escala de medida, tal como definida por Milton Meira do Nascimento ${ }^{69}$ e por Luiz Roberto Salinas Fortes ${ }^{70}$, é possível afirmar uma afinidade envolvendo o Discurso sobre a desigualdade, o Ensaio e o Contrato social.

O autor do Contrato pretendia construir um modelo teórico da sociedade humana, que não corresponde a nenhuma realidade observável, mas graças ao qual conseguimos julgar o estado presente de todas as sociedades históricas. Rousseau apresenta com muita precisão os objetivos da redação de seu livro. Ele visa a julgar as instituições ou o direito positivo dos governos estabelecidos. Para tanto, é necessário estipular regras e princípios a fim de direcionar as observações e conduzir os julgamentos: tal é o papel que os princípios do direito político vieram exercer. Desse modo, recusando a representação do poder soberano ou da esfera legislativa ao afirmar que a vontade não se representa, Rousseau estabelece os princípios de legitimidade do corpo político ou o princípio de constituição originária de uma comunidade política: a soberania deve residir no povo e este não pode confiar seu exercício aos governantes, quaisquer que sejam eles. Portanto, o único Estado legítimo é aquele em que o próprio povo exerce a soberania, isto é, onde o povo é o autor das leis às quais ele próprio deverá obedecer. Com isso, ao analisar os Estados existentes e constatar que eles estabeleceram representantes e deputados encarregados de exercer o poder legislativo, podemos, de acordo com as regras de observação anteriormente construídas, julgá-los ilegítimos ou considerá-los como Estados desprovidos de liberdade.

No Emílio, o cidadão de Genebra afirma que

quem quer julgar de modo sadio os governos tal como existem é obrigado a reunir os dois estudos [isto é, os princípios do direito político e o direito positivo dos governos estabelecidos]; é preciso saber o que deve ser para bem julgar o que é. [...] Antes de observar, é preciso estabelecer regras para as observações, é preciso fabricar uma escala para nela marcar as medidas que se tiram. Nossos princípios do direito político são essa escala. Nossas medidas são as leis políticas de cada país. ${ }^{71}$

Logo na sequência, o autor complementa:

${ }^{69}$ NASCIMENTO, "O Contrato social - entre a escala e o programa".

70 SALINAS FORTES, Paradoxo do espetáculo: política e poética em Rousseau, p. 81.

${ }^{71}$ ROUSSEAU, Émile ou de l'éducation, OC, IV, pp. 836-837. 
dir-se-ia que construímos nosso edifício com madeira, e não com homens, tamanha a exatidão com que alinhamos cada peça! É verdade, meu amigo, mas lembra-te que o direito não se dobra às paixões dos homens e que estávamos tratando de estabelecer os verdadeiros princípios do direito político. Agora que nossos fundamentos estão assentados, vem examinar o que os homens construíram sobre eles e verás lindas coisas! $!^{72}$

Rousseau propõe no Contrato social formular os princípios do direito político sem se ocupar com determinado governo particular, sem sair dos limites de uma discussão geral e abstrata. Mas, uma vez realizado este propósito, cabe avaliar cada país, observando seu grau de concordância com tais princípios. O Contrato, portanto, pode ser considerado como uma grande escala de medida através da qual se avalia cada povo e cada país, inserindo-os em pontos determinados dessa escala que vai desde o grau máximo de servidão e corrupção até o grau máximo de liberdade civil ou política. As sociedades históricas estariam posicionadas nesta escala, sem que nenhuma delas jamais alcance ou jamais tenha alcançado o modelo originário.

Rousseau redige o Discurso sobre a desigualdade a fim de responder à questão proposta pela academia de Dijon de saber qual é a origem da desigualdade entre os homens e se ela é autorizada pela natureza. Para tanto, o autor procura elaborar a imagem hipotética e original do homem "tal como a natureza o formou" 73 , despindo-o de todos aqueles atributos que as circunstâncias e os progressos humanos acrescentaram a seu estado primitivo ou nele mudaram. O que interessa é diagnosticar o estado atual das coisas e explicar a tirania (constatada nas formas de governo da Europa) por meio da elaboração de um parâmetro de comparação, inserindo os povos e as sociedades em pontos distintos da escala de acordo com o grau de proximidade e de distanciamento em relação ao modelo teórico estabelecido. Os Caraíbas e os Hotentotes estão mais próximos do modelo construído, ao passo que os europeus modernos e civilizados encontram-se mais afastados.

Lógica semelhante perpassa o modelo ideal de linguagem e de língua elaborado no Ensaio e Salinas Fortes havia já sugerido esta hipótese em seu Paradoxo do espetáculo ${ }^{74}$. A presença do acento nas línguas - propiciando a consubstancialidade originária entre língua e música - serve tanto como uma escala ou um paradigma capaz de medir a posição que as diversas línguas ou linguagens históricas assumem quanto para explicar o afastamento das sociedades modernas ocidentais, nas quais o lugar da fala melhor se definiria como um não lugar. Ou seja, o modelo originário de linguagem estabelecido por Rousseau funciona como um parâmetro capaz de bem conduzir a avaliação das diferentes línguas e de suas respectivas sociedades. Parafraseando Rousseau, trata-se da fabricação de um modelo - hipotético, é verdade -, mas sobre o qual são necessárias noções exatas para bem julgar tanto o estado atual dos diferentes povos quanto o estado de suas línguas. Temos assim o ideal de uma língua pura, destituída de toda e qualquer relação com o lugar e com a esfera social. Em suma,

72 ROUSSEAU, Émile ou de l'éducation, OC, IV, p. 849.

73 ROUSSEAU, Discours sur l'origine de l'inégalité, OC, III, p. 122.

74 SALINAS FORTES, Paradoxo do espetáculo: política e poética em Rousseau, pp. 83-84. 
uma ficção ou uma baliza teórica para conduzir a interpretação da realidade empírica. Neste debate geral não importam as línguas particulares, os processos de construção de suas identidades e diferenças, tampouco suas respectivas histórias. As línguas históricas existentes entram apenas posteriormente para serem avaliadas.

\section{Considerações finais}

Um dos vieses interpretativos da história da diversificação linguístico-cultural humana presentes na obra de Rousseau é aquele que parte de um tipo ideal originário e considera as variações como uma degeneração e um afastamento em relação a este tipo. De um lado, existiria um tipo primitivo e originário e, de outro, a(s) história(s) das alterações e dos desvios desse tipo, isto é, a degeneração desse modelo originário.

O problema de generalizar essa leitura é que o próprio autor havia dito ao fim do capítulo II do Ensaio que a origem única e geral da língua não pode ser considerada "indistintamente verdadeira". Ela é verdadeira, mas não indistintamente verdadeira, sendo pois necessário inserir as condições locais e materiais de existência na formação e desenvolvimento da diversidade linguística. Assim, a diferença entre as línguas é reconhecida apenas a partir das diferenças de lugares nos quais elas se originam, a partir das transformações constantes desses mesmos lugares (implicando alterações nas línguas) e da relação com a esfera social e os processos de socialização. O autor desenvolve uma preocupação com os processos que levaram à constituição da realidade empírica sem que a baliza teórica de tipo ideal originário tenha lugar ou demasiada importância. Contra o etnocentrismo, este outro viés interpretativo multiplica as origens de modo a afirmar positivamente as diferenças, aspirando entendê-las enquanto tais, independente de uma referência a um modelo originário. Sendo assim, a lógica do desvio não é a única possível nem a melhor expressão do pensamento antropológico do autor.

Não obstante, Rousseau quer avaliar a situação presente e o estado atual das coisas. E, para tanto, reintroduz o tipo primitivo-defletivo no interior da ideia de escala de medida. Nestes termos, depois de ter detalhado a natureza e os elementos distintivos da língua acentuada dos primeiros tempos, de duração meramente ficcional, é possível inserir cada uma das línguas históricas em uma posição de acordo com o grau de proximidade ou afastamento em relação ao modelo fabricado.

Desse modo, dois vieses interpretativos aparecem e são igualmente válidos: 1) um modelo que pretende ler o estado presente de diversidade linguística por meio da distância em relação ao tipo ideal originário, 2) outro de viés antropológico que pretende mostrar a formação da diversidade, explicando as origens e as diferenças entre as línguas. Ambas as perspectivas compõem um quadro no qual vemos de forma privilegiada o modo como as reflexões linguísticas de Rousseau transitam entre o julgamento histórico e o saber antropológico. 


\section{ORIGIN AND ALTERATION IN ROUSSEAU'S LINGUISTIC-MUSICAL THINKING}

Abstract: Rousseau's linguistics moves between two distinct, but equally, valid directions, namely, anthropological knowledge and the historical judgment of the present. The main objective of this work is to present each one of these directions: the last one is based on a unique and original model of language (a protolanguage) that gradually and historically would degenerate, becoming corrupted; whereas the first one multiplies its origins in order to positively affirm the existence of differences, explaining them as such. One of them constitutes a scale of measurement, another one is an antidote against ethnocentrism.

Keywords: Rousseau - language - music - anthropology - history.

\section{REFERÊNCIAS BIBLIOGRÁFICAS}

BANDERA, Mauro Dela. "Questões de cronologia rousseauísta: o caso do Ensaio sobre a origem das línguas”. In: Revista de Filosofia Trans/form/ ação. UNESP Marília-SP, p. 167-186, 2019.

BECKER, Evaldo. "Política e linguagem em Rousseau e Condillac". Kriterion, Belo Horizonte, v. 52, n. 123, pp. 49-74, 2011.

. Politica e linguagem em Rousseau. São Cristóvão: Ed. UFS, 2016.

CONDILLAC. Essai sur l'origine des connaissances humaines. Paris: J. Vrin, 2014.

DERRIDA, Jacques. De la Grammatologie. Paris: Éditions de Minuit, 1967.

DUCLOS, Charles Pinot. Remarques sur la grammaire générale et raisonnée. In: ARNAULD, Antoine; LANCELOT, Claude. Grammaire générale et raisonnée de Port-Royal. Genève: Slatkine Reprints, 1993.

HORÁCIO. Arte Poética. In: A poética clássical Aristóteles, Horácio, Longino. Tradução de Jaime Bruna. São Paulo: Cultrix, 2005.

KINTZLER, Catherine. Rameau et Rousseau: le choc de deux esthétiques. In: ROUSSEAU, Jean-Jacques. Préface aux Écrits sur la musique. Paris: Éditions Stock, 1979.

LEFEBVRE, Philippe. L'esthétique de Rousseau. Paris: Editions SEDES, 1997.

MOSCONI, Jean. "Analyse et genèse: regards sur la théorie du devenir de l'entendement au XVIIIème siècle”. In: Cahiers pour l'Analyse, Paris, n. 4, 1966.

NASCIMENTO, Milton Meira do. "O Contrato social - entre a escala e o programa". In: Discurso, no 17. São Paulo: Editora Polis, 1988.

PRADO JÚNIOR, Bento. A retórica de Rousseau e outros ensaios. Tradução de Cristina Prado. São Paulo: Cosac Naify, 2008.

RIBEIRO, Lucas. "Linguagem e política: Rousseau leitor de Charles Duclos". Cadernos de Ética e Filosofia Politica, v. 1, n. 34, p. 143-152, 2019. 
ROUSSEAU, J-J. Du Principe de la mélodie ou réponse aux erreurs sur la musique. In: WOKLER, Robert. Rousseau on society, politics, music and language (Texte imprimé): an historical interpretation of his early writings. New York: Garland, pp. 436-482, 1987.

Cuures Complètes de Jean-Jacques Rousseau. Ed. Bernard Gagnebin e Marcel Raymond. Paris: Gallimard, 1959-1995. 5 volumes. (Col. Bibliothèque de la Pléiade).

SALINAS FORTES, Luiz Roberto. Paradoxo do espetáculo: política e poética em Rousseau. São Paulo: Discurso editorial, 1997.

SOUZA, Maria das Graças de. Ilustração e história: o pensamento sobre a história no iluminismo francês. São Paulo: Discurso Editorial, 2001.

STAROBINSKI, Jean. Jean-Jacques Rousseau: a transparência e o obstáculo, seguido de sete ensaios sobre Rousseau. Tradução de Maria Lúcia Machado. São Paulo: Companhia das Letras, 1991.

VALÉRY, Paul. Introduction à la Méthode de L. de Vinci. Paris: Ed. Gallimard, 1957.

WYSS, André. Jean-Jacques Rousseau: l'accent de l'écriture. Neuchâtel: Editions de la Baconnière, 1988.

YASOSHIMA, Fábio. Entre o canto das paixões e os artifícios da harmonia: o pensamento musical de Rousseau contra o sistema harmônico de Rameau. Tese (Doutorado em Filosofia) - Faculdade de Filosofia, Letras e Ciências Humanas da Universidade de São Paulo, São Paulo/SP, 2017. 